\title{
Degradation of Methylene blue and Rhodamine B as Water Pollutants via Green Synthesized $\mathrm{Co}_{3} \mathrm{O}_{4} / \mathrm{ZnO}$ Nanocomposite
}

\author{
Mohammad Hassanpour, Hossein Safardoust-Hojaghan, Masoud Salavati-Niasari * \\ Institute of Nano Science and Nano Technology, University of Kashan, Kashan, P.O. Box 87317-51167, I. R. \\ Iran
}

\begin{abstract}
Methylene blue (MB) and Rhodamine $B(\mathrm{RB})$ are produced as water pollutants in textile, plastic and dye industries. Many studies have investigated to remove RB and MB in wastewater of industries. At present work, $\mathrm{Co}_{3} \mathrm{O}_{4} / \mathrm{ZnO}$ nanocomposite is applied for removal of $\mathrm{MB}$ and $\mathrm{RB}$ dyes from water. Eco friendly, $\mathrm{Co}_{3} \mathrm{O}_{4} / \mathrm{ZnO}$ is synthesized via microwave assisted method. Results showed that uniform morphology and size particle is obtained at $10 \mathrm{~min}$ and $900 \mathrm{~W}$ as optimum time and power. Synthesized $\mathrm{Co}_{3} \mathrm{O}_{4} / \mathrm{ZnO}$ is characterized with $\mathrm{X}$-ray diffraction (XRD) analysis, Transmission Electron Microscopy (TEM), Fourier transform infrared (FT-IR) spectroscopy, Scanning Electron Microscopy (SEM) and vibrating sample magnetometers (VSM). Prepared nanocomposite shows excellent photo degradation behavior toward MB and RB under UV light. Photo degradation efficiency is calculated 80 and $90 \%$ for $\mathrm{MB}$ and $\mathrm{RB}$ respectively.
\end{abstract}

Keywords: Pollutant; Nanocomposite; Microwave; Magnetic; Photocatalytic; Nanostructures.

\section{Introduction}

Water pollution is converted to one of the greatest environmental concern. It can be creating with entering toxic substance into water bodies such as lakes, rivers, oceans and so on, getting dissolved in them, lying suspended in the water or depositing on the bed, so decreases quality of water $[1,2]$. Dyes 
are one of the most important pollutant that can produce from sources such as textile, paint, paper and plastic industrial[3].

Methylene blue (MB) and Rhodamine B (RB) are heterocyclic dyes that has wide industrial application, but cause serious environmental problems because of its high toxicity and accumulation in the environment. Till now, many efforts have been done for removal or separation of MB and RB from water [4-6].

One of the effective method for decreasing of water pollutants is photocatalytic degradation of pollutants. Nanocomposites can act as suitable photocatalytic agent [7, 8]. ZnO based nanocomposites are very interesting for photocatalytic degradation for its advantages such as direct band gap, anisotropic growth, high electron mobility and simple controlling of its morphology [9, 10]. On the other hand, $\mathrm{Co}_{3} \mathrm{O}_{4}$ has dual attractive properties for its magnetic and semiconducting properties [11, 12]. For this, $\mathrm{Co}_{3} \mathrm{O}_{4}$ nanostructures has found potential application in different fields such as supercapacitor [11], photo electrochemical water splitting [13], gas sensor [14], lithium ion batteries [15]. Till now, many studies have been assigned to investigate $\mathrm{ZnO}$ and $\mathrm{Co}_{3} \mathrm{O}_{4}$ nanostructures separately, but there are limited research on investigation of $\mathrm{Co}_{3} \mathrm{O}_{4} / \mathrm{ZnO}$ nanocomposite [16-18]. Presence of magnetic nanostructure in nanocomposite has more benefit for photocatalytic process such as simple separation and recovery of catalyst, directed delivery of particle and effective remedial of the desired site [19]. For $\mathrm{Co}_{3} \mathrm{O}_{4} / \mathrm{ZnO}$, all efforts have divided in two main parts; synthesis and application. Recently, Ghose and et al have synthesized $\mathrm{Co}_{3} \mathrm{O}_{4} / \mathrm{ZnO}$ nanocomposite via homogenous precipitation method. From the magnetic measurements, they found that $\mathrm{Co}_{3} \mathrm{O}_{4} / \mathrm{ZnO}$ nanocomposite shows weak ferromagnetic behavior at low temperature (10K)[20]. Baykal et al have synthesized superparamagnetic $\mathrm{Co}_{3} \mathrm{O}_{4} / \mathrm{ZnO}$ via sequential polyol method. Firstly, they synthesized $\mathrm{Co}_{3} \mathrm{O}_{4}$ and $\mathrm{ZnO}$ introduced on the surface of synthesized $\mathrm{Co}_{3} \mathrm{O}_{4}$ nanoparticles in the same pot. They found that prepared nanocomposite 
shows superparamagnetic behavior at room temperature[21]. Chronakis et al have synthesized $\mathrm{Co}_{3} \mathrm{O}_{4} / \mathrm{ZnO}$ hierarchical nanostructures by electrospinning and hydrothermal methods. They produced $\mathrm{Co}_{3} \mathrm{O}_{4}$ nanofibers with rough surfaces containing $\mathrm{ZnO}$ nanoparticles[22]. Maestrelli et al have synthesized $\mathrm{Co}_{3} \mathrm{O}_{4} / \mathrm{ZnO}$ particles by high energy milling and evaluate photocatalytic properties. They found that starting materials obtain in a micrometric scale[23]. At the other work, Ananthakrishnan et al have prepared $\mathrm{Co}_{3} \mathrm{O}_{4} / \mathrm{ZnO}$ heteronanostructures. They showed that prepared nanocomposite has high surface area, higher separation of electrons and holes and porous structure led to the promising visible light photocatalytic properties [17].

In this study, first step, $\mathrm{Co}_{3} \mathrm{O}_{4} / \mathrm{ZnO}$ nanocomposite is synthesized via microwave method as green and fast method. Prepared nanocomposite is characterized with XRD, TEM, SEM, EDS, VSM. Finally, $\mathrm{Co}_{3} \mathrm{O}_{4} / \mathrm{ZnO}$ nanocomposite is introduced to $\mathrm{MB}$ and $\mathrm{RB}$ containing water to investigate photocatalytic degradation of MB and RB under UV light.

\section{Experimental}

\subsection{Materials and methods}

$\mathrm{Co}\left(\mathrm{CH}_{3} \mathrm{COO}\right)_{2} \cdot 4 \mathrm{H}_{2} \mathrm{O}, \mathrm{Zn}\left(\mathrm{CH}_{3} \mathrm{COO}\right)_{2} \cdot 2 \mathrm{H}_{2} \mathrm{O}$, ethylene glycol was purchased from Merck and all the chemicals were used as received without further purifications. Room temperature magnetic properties were investigated using an alternating gradient force magnetometer (AGFM) device, (made by Meghnatis Daghigh Kavir Company, Iran) in an applied magnetic field sweeping between \pm 10000 Oe. XRD patterns were recorded by a Philips, X-ray diffractometer using Ni-filtered $\mathrm{CuK}_{\alpha}$ radiation. Fourier transform infrared (FT-IR) spectra were detected by means of Nicolet Magna-550 spectrometer in $\mathrm{KBr}$ pellets. SEM images were obtained using a LEO instrument model 1455VP. Prior to taking images, the samples were coated by a very thin layer of Pt (using a BAL-TEC SCD 005 sputter coater) to make the sample surface conductor and prevent charge accumulation, and obtaining a better contrast. 
Transmission electron microscopy (TEM) image was achieved via a Philips EM208 transmission electron microscope with an accelerating voltage of $200 \mathrm{kV}$.

\subsection{Synthesis of $\mathrm{ZnO} / \mathrm{Co}_{3} \mathrm{O}_{4}$ nanoparticles}

$\mathrm{Co}\left(\mathrm{CH}_{3} \mathrm{COO}\right)_{2} \cdot 4 \mathrm{H}_{2} \mathrm{O}$ and of $\mathrm{Zn}\left(\mathrm{CH}_{3} \mathrm{COO}\right)_{2} .2 \mathrm{H}_{2} \mathrm{O}$ with $1: 1$ molar ratio were dissolved in different volume of ethylene glycol according Table 1. Then, transparent solution was exposed to microwave irradiation at various time and power according Table1. The obtained precipitate was washed twice with methanol and dry at $80{ }^{\circ} \mathrm{C}$ for $5 \mathrm{~h}$. Finally, the product was calcined at $400{ }^{\circ} \mathrm{C}$ for $2 \mathrm{~h}$. Color of final product was black.

\subsection{Photocatalytic test}

Photocatalytic activity of $\mathrm{Co}_{3} \mathrm{O}_{4} / \mathrm{ZnO}$ nanocomposite was carried out by monitoring the degradation of methylene blue and rhodamine B in aqueous solution, under irradiation with UV light. Degradation process was performed in a quartz photocatalytic reactor. Photocatalytic degradation was carried out with $10 \mathrm{ppm}$ solution of dyes and $0.01 \mathrm{~g}$ of nanocomposite. Then the mixture was placed in photoreactor under UV light and stirred for $30 \mathrm{~min}$ at dark to ensure proper adsorption-desorption equilibrium of the dye molecules on the nanostructures surface required to act as an efficient photocatalyst. To maintain the solution oxygen-saturated throughout the reaction, air was blown into the vessel via a pump. Then $\mathrm{Co}_{3} \mathrm{O}_{4} / \mathrm{ZnO}$ was separated from the $5 \mathrm{ml}$ samples, taken from the degraded solution at various time intervals, using 5 min centrifuging at 12,000 rpm. The dye concentration was determined with aid of a UV-vis spectrophotometer.

\section{Results and discussion}

XRD pattern of $\mathrm{Co}_{3} \mathrm{O}_{4} / \mathrm{ZnO}$ is shown in Fig. 1. As well as show, XRD pattern confirms presence of both hexagonal phase of $\mathrm{ZnO}$ (JCPDS No.80-0075, space group: P63mc) and cubic phase of $\mathrm{Co}_{3} \mathrm{O}_{4}$

(JCPDS No 80-1535., Fd-3m). also, XRD pattern shows formation of $\mathrm{ZnO}$ and $\mathrm{Co}_{3} \mathrm{O}_{4}$ without 
impurity. crystalline sizes is calculated from Scherrer equation, $D_{c}=K \lambda / \beta \operatorname{Cos} \theta$, where $\beta$ is the width of the observed diffraction peak at its half maximum intensity (FWHM), $\mathrm{K}$ is the shape factor, which takes a value of about 0.9 , and $\lambda$ is the $\mathrm{X}$-ray wavelength $\left(\mathrm{CuK}_{\alpha}\right.$ radiation, equals to $\left.0.154 \mathrm{~nm}\right)$ were about $18 \mathrm{~nm}$ for $\mathrm{Co}_{3} \mathrm{O}_{4} / \mathrm{ZnO}$ nanocomposite.

Fig. 2 shows FT-IR spectrum of synthesized $\mathrm{Co}_{3} \mathrm{O}_{4} / \mathrm{ZnO}$ nanocomposite. The absorption peak at 3349 $\mathrm{cm}^{-1}$ related to the stretching vibrational absorptions of OH. 479,574 and $664 \mathrm{~cm}^{-1}$ corresponded to the stretching vibration of $\mathrm{Zn}-\mathrm{O}, \mathrm{Co}^{+2}-\mathrm{O}$ and $\mathrm{Co}^{3+}-\mathrm{O}$ respectively. EDS analysis is used to provide further evidence for the components. EDS analysis confirms presence of cobalt, zinc and oxygen elements without any impurity (Fig. 3).

For investigation morphology of nanocomposite scanning electron microscopy (SEM) was applied. Morphology and size of nanocomposite play important role on photocatalytic activity. So synthesis procedure is done at various condition for obtaining optimum. Fig. 4 shows effect of cyclic microwave irradiation on size and morphology of $\mathrm{Co}_{3} \mathrm{O}_{4} / \mathrm{ZnO}$ nanocomposite. One cycle is 1 min long and composes of irradiation and non-irradiation for 30 second each. Size of particles at continuously state is less than cyclic state. When cyclic microwave irradiation is applied, growth of particles overcomes to nucleation at power off period. This can lead to aggregation of particles.

Fig. 5 illustrates effect of microwave power on particle size. For investigation, 750 and $900 \mathrm{~W}$ is applied. SEM images confirm that when power of microwave irradiation increase, size of particles decrease. When power of microwave increases, rate of nucleation increases and rate of particles growth decrease, it causes particle size decrease.

Fig. 6 shows effect of irradiation time on particle size of nanocomposite at 900W. It is obvious that at 10 min particles are smaller and homogenous. 
Solvent type and volume play key role in microwave assisted synthesis. The volume of solvent had a significant impact upon the electric field distribution. The use of excellent microwave absorbing solvents results in high heating rates. The solvents used in microwave heating can be classified on the basis of their loss tangent $(\tan \delta)$ : high $(\tan \delta>0.5)$, medium $(\tan \delta \approx 0.1-0.5)$, and low $(\tan \delta<0.1) \cdot \tan \delta$ of ethylene glycol is 1.17 , so it can be good candidate for microwave assisted synthesis[24, 25]. Fig. 7 shows when volume of used ethylene glycol increases, particle size decrease. Here, ethylene glycol has dual task; solvent and capping agent. So, with decreasing of ethylene glycol, agglomeration is occurred. Fig. 8 shows TEM image of nanocomposite at two magnifications. Obviously, TEM images confirm formation of nanocomposite. It is clear that morphology of product is particle. Average particle size from TEM image is calculated 30nm.

The magnetization measurements as a function of the magnetic field are studied at $300 \mathrm{~K}$, and the hysteric curve with nearly saturated nature at high fields is shown in Fig. 9. For presence of $\mathrm{Co}_{3} \mathrm{O}_{4}$, $\mathrm{Co}_{3} \mathrm{O}_{4} / \mathrm{ZnO}$ obtain magnetic property and there is no magnetic contribution of $\mathrm{ZnO}$ at room temperature. VSM analysis shows that $\mathrm{Co}_{3} \mathrm{O}_{4} / \mathrm{ZnO}$ nanocomposite has ferromagnetic properties. The saturation magnetization and coercivity are found $0.13 \mathrm{emu} / \mathrm{g}$ and 287 Orsted respectively.

Diffuse reflectance spectra (DRS) of $\mathrm{Co}_{3} \mathrm{O}_{4} / \mathrm{ZnO}$ nanocomposite in Fig. 10 illustrates optical absorption capability in the region from 200-500nm. The optical energy band gap of nanocomposite was determined using the relation:

$(\alpha \mathrm{h} \vartheta)=\mathrm{C}(\mathrm{h} \vartheta-\mathrm{Eg})^{1 / 2}$. For this nanocomposite three band gap determined: 1.8 and $2.79 \mathrm{ev}$ for $\mathrm{Co}_{3} \mathrm{O}_{4}$ and $3.9 \mathrm{eV}$ for $\mathrm{ZnO}$. Calculated band gap reveals that prepared nanocomposite can be used as good catalyst in photocatalyst process.

For investigation of photocatalytic activity, $\mathrm{Co}_{3} \mathrm{O}_{4} / \mathrm{ZnO}$ nanocomposite are used. The photocatalytic efficiency was calculated using the following (Eq (1)): 
Color Removal $(\%)=\left(\mathrm{C}_{0}-\mathrm{C}_{\mathrm{t}} / \mathrm{C}_{0}\right) \times 100$

Where $\mathrm{C}_{0}\left(\mathrm{mgL}^{-1}\right)$ is the initial concentration of $\mathrm{MB}$ and $\mathrm{RB}$ in solution, and $\mathrm{C}_{\mathrm{t}}\left(\mathrm{mgL}^{-1}\right)$ is the concentration of $\mathrm{MB}$ and $\mathrm{RB}$ at any irradiation time $\mathrm{t}(\mathrm{min})$.

Fig. 11 shows for RB and MB, after 90 minutes, $91 \%$ and $86 \%$ of pollutant was degraded respectively. The band position of $\mathrm{Co}_{3} \mathrm{O}_{4} / \mathrm{ZnO}$ system can lead to charge transfer from $\mathrm{Co}_{3} \mathrm{O}_{4}$ to $\mathrm{ZnO}$. So, recombination of electron-hole possibility in $\mathrm{Co}_{3} \mathrm{O}_{4}$ becomes small and causes holes in valance band react with $\mathrm{OH}$ groups on the surface of nanocomposite and convert them to highly reactive $\mathrm{OH} \bullet$ radicals. Produced radicals react with $\mathrm{RB}$ and $\mathrm{MB}$ and degraded. The kinetics of the photocatalytic decolourization rate of MB was determined using the Langmuir-Hinshelwood kinetics model, as given in the following $(\mathrm{Eq}(2))$ :

$\operatorname{Ln}\left(\mathrm{C}_{0} / \mathrm{C}_{\mathrm{t}}\right)=\mathrm{k}_{\mathrm{app}} \mathrm{t}$

The pseudo-first-order rate constant, kapp $\left(\mathrm{min}^{-1}\right)$, was calculated from the slope of $\ln \left(\mathrm{C}_{\mathrm{o}} / \mathrm{C}_{\mathrm{t}}\right)$ versus irradiation time t[26].

In a similar reported study, the photocatalytic degradation of $\mathrm{RB}$ was studied with $\mathrm{Co}_{3} \mathrm{O}_{4} / \mathrm{ZnO}$. They found when the aqueous solution of dye with sample is exposed in light, the degradation rate is quit fast and dye is almost completely (89\%) decomposed within 400min[19]. In another work, photocatalytic degradation of $\mathrm{MB}$ was performed with $\mathrm{Co}_{3} \mathrm{O}_{4} / \mathrm{ZnO}$ core/shell nanorods. They found compared with a single component of $\mathrm{Co}_{3} \mathrm{O}_{4}$ nanorods, $\mathrm{Co}_{3} \mathrm{O}_{4} / \mathrm{ZnO}$ core/shell nanorods enhance photocatalytic performance because of the efficient separation of photogenerated electron-hole pairs[27].

\section{Conclusion}

summary, $\mathrm{Co}_{3} \mathrm{O}_{4} / \mathrm{ZnO}$ nanocomposite is prepared for removal of $\mathrm{MB}$ and $\mathrm{RB}$ dyes from water. For presence of $\mathrm{Co}_{3} \mathrm{O}_{4}, \mathrm{Co}_{3} \mathrm{O}_{4} / \mathrm{ZnO}$ nanocomposite had magnetic property that cause simple separation and reuse of catalyst. Eco friendly, $\mathrm{Co}_{3} \mathrm{O}_{4} / \mathrm{ZnO}$ is synthesized via microwave assisted method. optimum 
time and power are obtained $10 \mathrm{~min}$ and $900 \mathrm{~W}$ respectively. Results show that $\mathrm{Co}_{3} \mathrm{O}_{4} / \mathrm{ZnO}$ nanocomposite is synthesized homogenously, without further impurity. Prepared nanocomposite shows excellent photocatalytic behavior toward $\mathrm{MB}$ and $\mathrm{RB}$ under UV light, so that photodegradation efficiency is calculated 86 and $91 \%$ for $\mathrm{MB}$ and $\mathrm{RB}$ respectively.

\section{Acknowledgment}

Authors are grateful to the council of Iran National Science Foundation and University of Kashan for supporting this work by Grant No (159271/8079). 


\section{References}

[1] Z. Zhu, X. Tang, C. Ma, M. Song, N. Gao, Y. Wang, P. Huo, Z. Lu, Y. Yan, Fabrication of conductive and high-dispersed Ppy@ $\mathrm{Ag} / \mathrm{g}-\mathrm{C}_{3} \mathrm{~N}_{4}$ composite photocatalysts for removing various pollutants in water, Applied Surface Science, 387 (2016) 366-374.

[2] T.M. Albayati, A.A. Sabri, R.A. Alazawi, Separation of Methylene Blue as Pollutant of Water by SBA-15 in a Fixed-Bed Column, Arabian Journal for Science and Engineering, 41 (2016) 2409-2415.

[3] R.L. Pérez, G.M. Escandar, Experimental and chemometric strategies for the development of Green Analytical Chemistry (GAC) spectroscopic methods for the determination of organic pollutants in natural waters, Sustainable Chemistry and Pharmacy, 4 (2016) 1-12.

[4] S. Marković, A. Stanković, Z. Lopičić, S. Lazarević, M. Stojanović, D. Uskoković, Application of raw peach shell particles for removal of methylene blue, Journal of Environmental Chemical Engineering, 3 (2015) 716-724.

[5] K. Elghniji, M. Ksibi, E. Elaloui, Sol-gel reverse micelle preparation and characterization of Ndoped $\mathrm{TiO}_{2}$ : Efficient photocatalytic degradation of methylene blue in water under visible light, Journal of Industrial and Engineering Chemistry, 18 (2012) 178-182.

[6] P. Zhang, X. Hua, X. Teng, D. Liu, Z. Qin, S. Ding, CTAB assisted hydrothermal synthesis of lamellar $\mathrm{Bi}_{2} \mathrm{WO}_{6}$ with superior photocatalytic activity for rhodamine $\mathrm{b}$ degradation, Materials Letters, 185 (2016) 275-277.

[7] R. Ahmad, Z. Ahmad, A.U. Khan, N.R. Mastoi, M. Aslam, J. Kim, Photocatalytic systems as an advanced environmental remediation: Recent developments, limitations and new avenues for applications, Journal of Environmental Chemical Engineering, 4 (2016) 4143-4164.

[8] Y.-X. Zhao, D.-R. Liu, F.-F. Li, D.-F. Yang, Y.-S. Jiang, Preparation, characterization and photocatalytic activity of N-doped $\mathrm{NaTaO}_{3}$ nanocubes, Powder Technology, 214 (2011) 155-160. 
[9] N. Tripathy, R. Ahmad, H. Kuk, D.H. Lee, Y.-B. Hahn, G. Khang, Rapid methyl orange degradation using porous $\mathrm{ZnO}$ spheres photocatalyst, Journal of Photochemistry and Photobiology B: Biology, 161 (2016) 312-317.

[10] J. Huang, S. Liu, L. Kuang, Y. Zhao, T. Jiang, S. Liu, X. Xu, Enhanced photocatalytic activity of quantum-dot-sensitized one-dimensionally-ordered $\mathrm{ZnO}$ nanorod photocatalyst, Journal of Environmental Sciences, 25 (2013) 2487-2491.

[11] X. Sun, Z. Jiang, C. Li, Y. Jiang, X. Sun, X. Tian, L. Luo, X. Hao, Z.-J. Jiang, Facile synthesis of Co3O4 with different morphologies loaded on amine modified graphene and their application in supercapacitors, Journal of Alloys and Compounds, 685 (2016) 507-517.

[12] Z. Seidov, M. Açıkgöz, S. Kazan, F. Mikailzade, Magnetic properties of $\mathrm{Co}_{3} \mathrm{O}_{4}$ polycrystal powder, Ceramics International, 42 (2016) 12928-12931.

[13] J. He, Y. Peng, Z. Sun, W. Cheng, Q. Liu, Y. Feng, Y. Jiang, F. Hu, Z. Pan, Q. Bian, S. Wei, Realizing High Water Splitting Activity on $\mathrm{Co}_{3} \mathrm{O}_{4}$ Nanowire Arrays under Neutral Environment, Electrochimica Acta, 119 (2014) 64-71.

[14] C. Sun, X. Su, F. Xiao, C. Niu, J. Wang, Synthesis of nearly monodisperse $\mathrm{Co}_{3} \mathrm{O}_{4}$ nanocubes via a microwave-assisted solvothermal process and their gas sensing properties, Sensors and Actuators B: Chemical, 157 (2011) 681-685.

[15] J. Zheng, J. Liu, D. Lv, Q. Kuang, Z. Jiang, Z. Xie, R. Huang, L. Zheng, A Facile synthesis of flower-like $\mathrm{Co}_{3} \mathrm{O}_{4}$ porous spheres for the lithium-ion battery electrode, Journal of Solid State Chemistry, 183 (2010) 600-605.

[16] S. Park, S. Kim, H. Kheel, C. Lee, Oxidizing gas sensing properties of the n- $\mathrm{ZnO} / \mathrm{p}-\mathrm{Co}_{3} \mathrm{O}_{4}$ composite nanoparticle network sensor, Sensors and Actuators B: Chemical, 222 (2016) 1193-1200. 
[17] M. Rakibuddin, R. Ananthakrishnan, Porous $\mathrm{ZnO} / \mathrm{Co}_{3} \mathrm{O}_{4}$ heteronanostructures derived from nano coordination polymers for enhanced gas sorption and visible light photocatalytic applications, RSC Advances, 5 (2015) 68117-68127.

[18] D. Bekermann, A. Gasparotto, D. Barreca, C. Maccato, E. Comini, C. Sada, G. Sberveglieri, A. Devi, R.A. Fischer, $\mathrm{Co}_{3} \mathrm{O}_{4} / \mathrm{ZnO}$ Nanocomposites: From Plasma Synthesis to Gas Sensing Applications, ACS Applied Materials \& Interfaces, 4 (2012) 928-934.

[19] T.K. Jana, A. Pal, K. Chatterjee, Magnetic and photocatalytic study of $\mathrm{Co}_{3} \mathrm{O}_{4}-\mathrm{ZnO}$ nanocomposite, Journal of Alloys and Compounds, 653 (2015) 338-344.

[20] R.K. Sharma, R. Ghose, Synthesis of $\mathrm{Co}_{3} \mathrm{O}_{4}-\mathrm{ZnO}$ mixed metal oxide nanoparticles by homogeneous precipitation method, Journal of Alloys and Compounds, 686 (2016) 64-73.

[21] S. Shafiu, H. Kavas, A. Baykal, Synthesis and Characterization of Superparamagnetic $\mathrm{Co}_{3} \mathrm{O}_{4} @ \mathrm{ZnO}$ Nanocomposite, Journal of Superconductivity and Novel Magnetism, 27 (2014) 17511755.

[22] M.A. Kanjwal, F.A. Sheikh, N.A.M. Barakat, I.S. Chronakis, H.Y. Kim, $\mathrm{Co}_{3} \mathrm{O}_{4}-\mathrm{ZnO}$ hierarchical nanostructures by electrospinning and hydrothermal methods, Applied Surface Science, 257 (2011) 7975-7981.

[23] J.A. Dias, V.L. Arantes, A.S. Ramos, T.R. Giraldi, M.Z. Minucci, S.C. Maestrelli, Characterization and photocatalytic evaluation of $\mathrm{ZnO}-\mathrm{Co}_{3} \mathrm{O}_{4}$ particles obtained by high energy milling. Part I: Processing, physicochemical and thermal characterization, Ceramics International, 42 (2016) $1425-1431$.

[24] Y.-J. Zhu, F. Chen, Microwave-Assisted Preparation of Inorganic Nanostructures in Liquid Phase, Chemical Reviews, 114 (2014) 6462-6555. 
[25] A. Pimentel, J. Rodrigues, P. Duarte, D. Nunes, F.M. Costa, T. Monteiro, R. Martins, E. Fortunato, Effect of solvents on $\mathrm{ZnO}$ nanostructures synthesized by solvothermal method assisted by microwave radiation: a photocatalytic study, Journal of Materials Science, 50 (2015) 5777-5787.

[26] A.H. Jawad, N.S.A. Mubarak, M.A.M. Ishak, K. Ismail, W.I. Nawawi, Kinetics of photocatalytic decolourization of cationic dye using porous $\mathrm{TiO}_{2}$ film, Journal of Taibah University for Science, 10 (2016) 352-362.

[27] C. Dong, X. Xiao, G. Chen, H. Guan, Y. Wang, Synthesis and photocatalytic degradation of methylene blue over p-n junction $\mathrm{Co}_{3} \mathrm{O}_{4} / \mathrm{ZnO}$ core/shell nanorods, Materials Chemistry and Physics, $155(2015) 1-8$. 


\section{Figure caption}

Table 1. Different reaction condition

Fig 1. XRD pattern of $\mathrm{Co}_{3} \mathrm{O}_{4} / \mathrm{ZnO}$ nanocomposite prepared at 10 minute and $900 \mathrm{~W}$.

Fig 2. FT-IR spectra of $\mathrm{Co}_{3} \mathrm{O}_{4} / \mathrm{ZnO}$ nanocomposite prepared at 10 minute and $900 \mathrm{~W}$.

Fig 3. EDS spectra of $\mathrm{Co}_{3} \mathrm{O}_{4} / \mathrm{ZnO}$ nanocomposite.

Fig 4. SEM image of $\mathrm{Co}_{3} \mathrm{O}_{4} / \mathrm{ZnO}$ nanocomposite prepared by cyclic irradiation, in two magnifications.

Fig 5. SEM image of $\mathrm{Co}_{3} \mathrm{O}_{4} / \mathrm{ZnO}$ nanocomposite at different power a) $750 \mathrm{~W}$ b) $900 \mathrm{~W}$.

Fig 6. $\mathrm{SEM}$ image of $\mathrm{Co}_{3} \mathrm{O}_{4} / \mathrm{ZnO}$ nanocomposite at different time of irradiation a) $5 \mathrm{~min}$ b) 10 min c) 15 $\min$.

Fig 7. SEM image of $\mathrm{Co}_{3} \mathrm{O}_{4} / \mathrm{ZnO}$ nanocomposite in different mole ratio of solvent $1: 1: 450$, in two magnifications.

Fig 8. TEM image of $\mathrm{Co}_{3} \mathrm{O}_{4} / \mathrm{ZnO}$ nanocomposite prepared at 10 minute $900 \mathrm{~W}$.

Fig 9. Room temperature hysteresis loop of $\mathrm{Co}_{3} \mathrm{O}_{4} / \mathrm{ZnO}$ nanocomposite prepared at $10 \mathrm{~min} 900 \mathrm{~W}$.

Fig 10. Diffuse reflectance spectra (DRS) of $\mathrm{Co}_{3} \mathrm{O}_{4} / \mathrm{ZnO}$ nanocomposite prepared at 10 min $900 \mathrm{~W}$.

Fig 11. Photocatalytic activity of $\mathrm{Co}_{3} \mathrm{O}_{4} / \mathrm{ZnO}$ nanocomposite on degradation of $\mathrm{RhB}$ and $\mathrm{MO}$ 
Table 1

\begin{tabular}{cccc}
\hline Number & Mole ratio M1:M2:S & Power $(\mathbf{W})$ & Time (min) \\
\hline 1 & $1: 1: 290$ & 900 & 5 \\
2 & $1: 1: 290$ & 900 & 10 \\
3 & $1: 1: 290$ & 900 & 15 \\
4 & $1: 1: 450$ & 900 & 10 \\
5 & $1: 1: 290$ & 750 & 10 \\
6 & $1: 1: 290$ & 900 & Cyclic irradiation \\
7 & $1: 1: 290$ & 900 & \\
\hline
\end{tabular}


Fig. 1

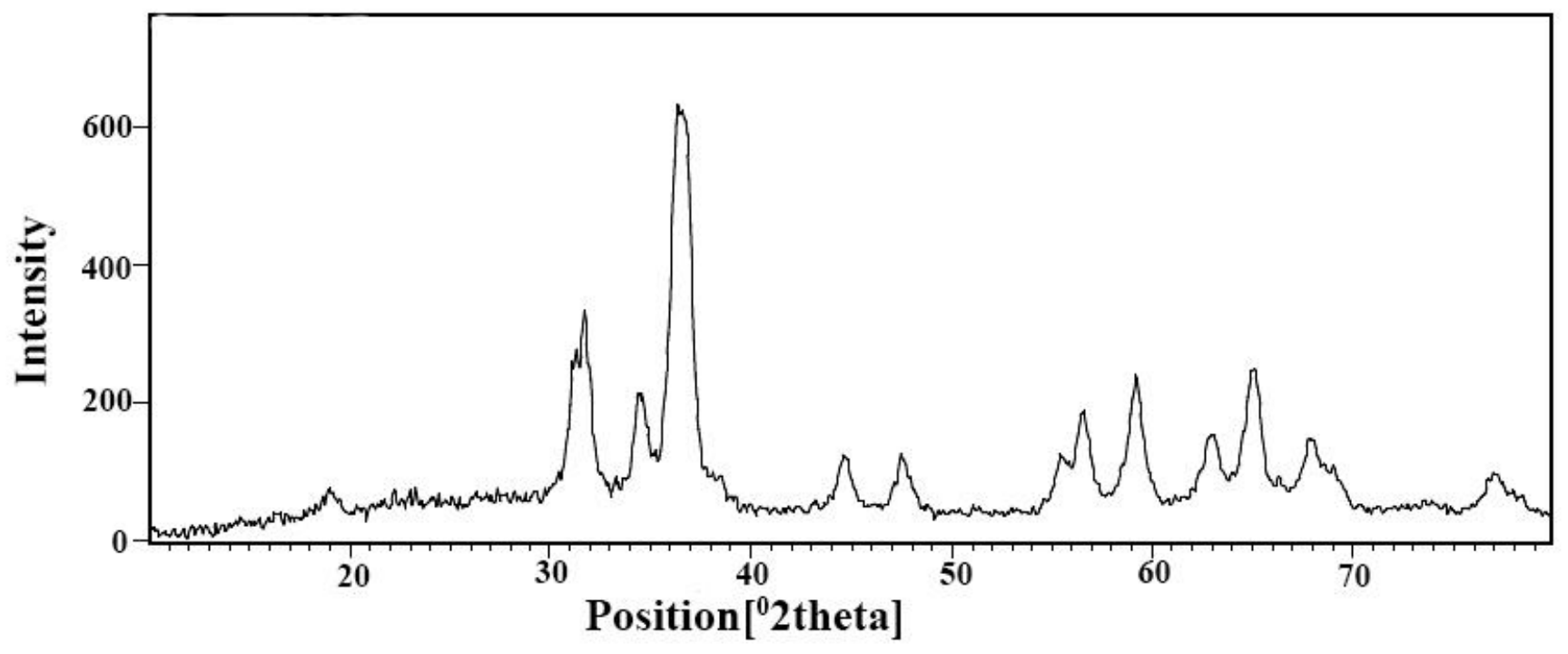

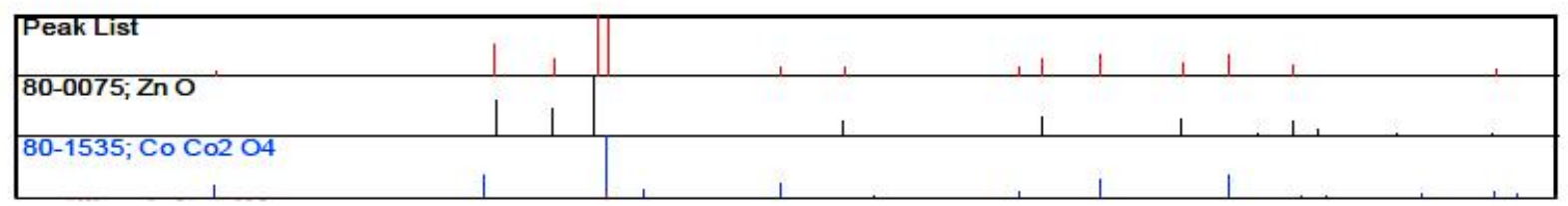


Fig. 2

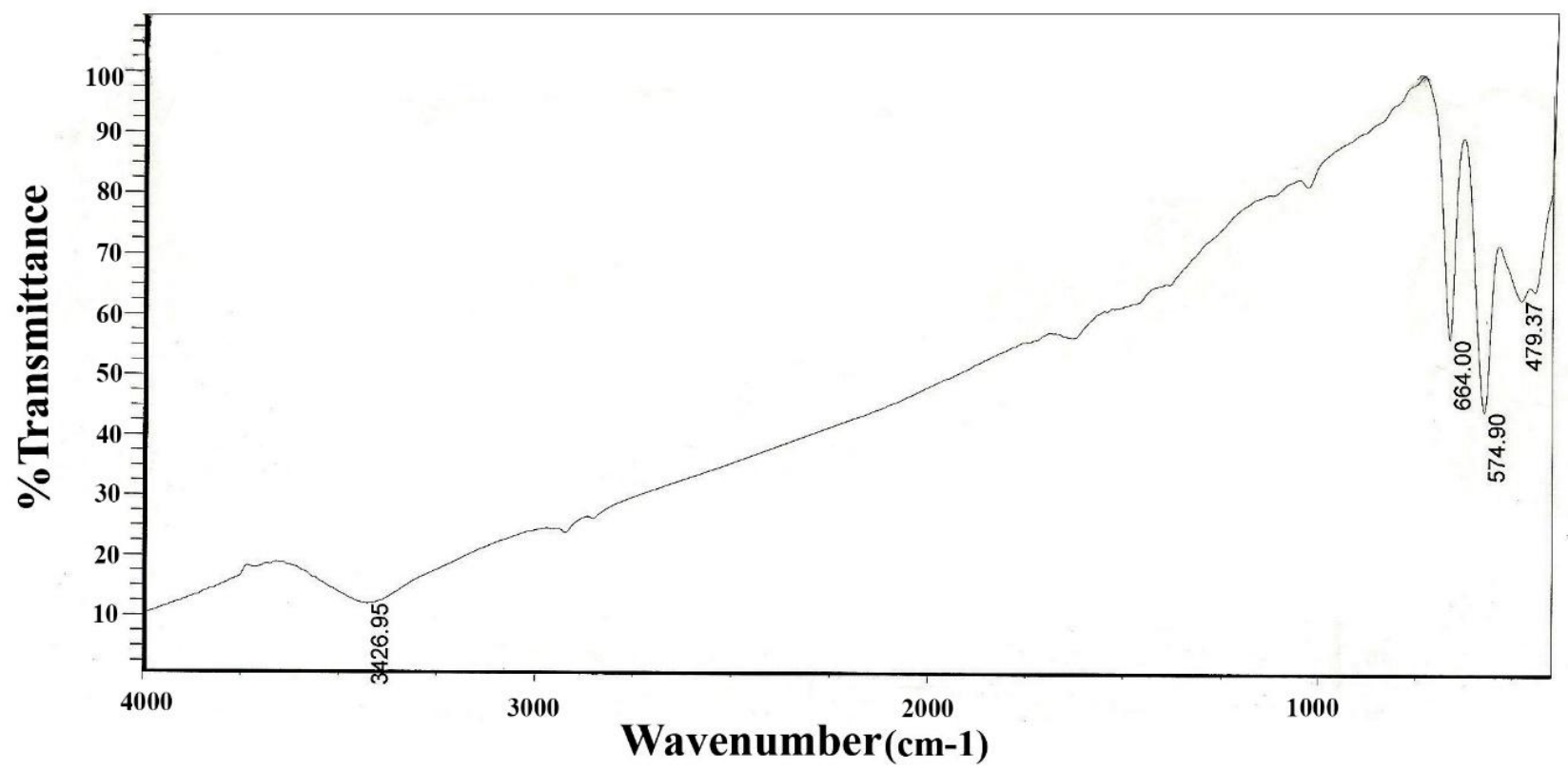


Fig. 3

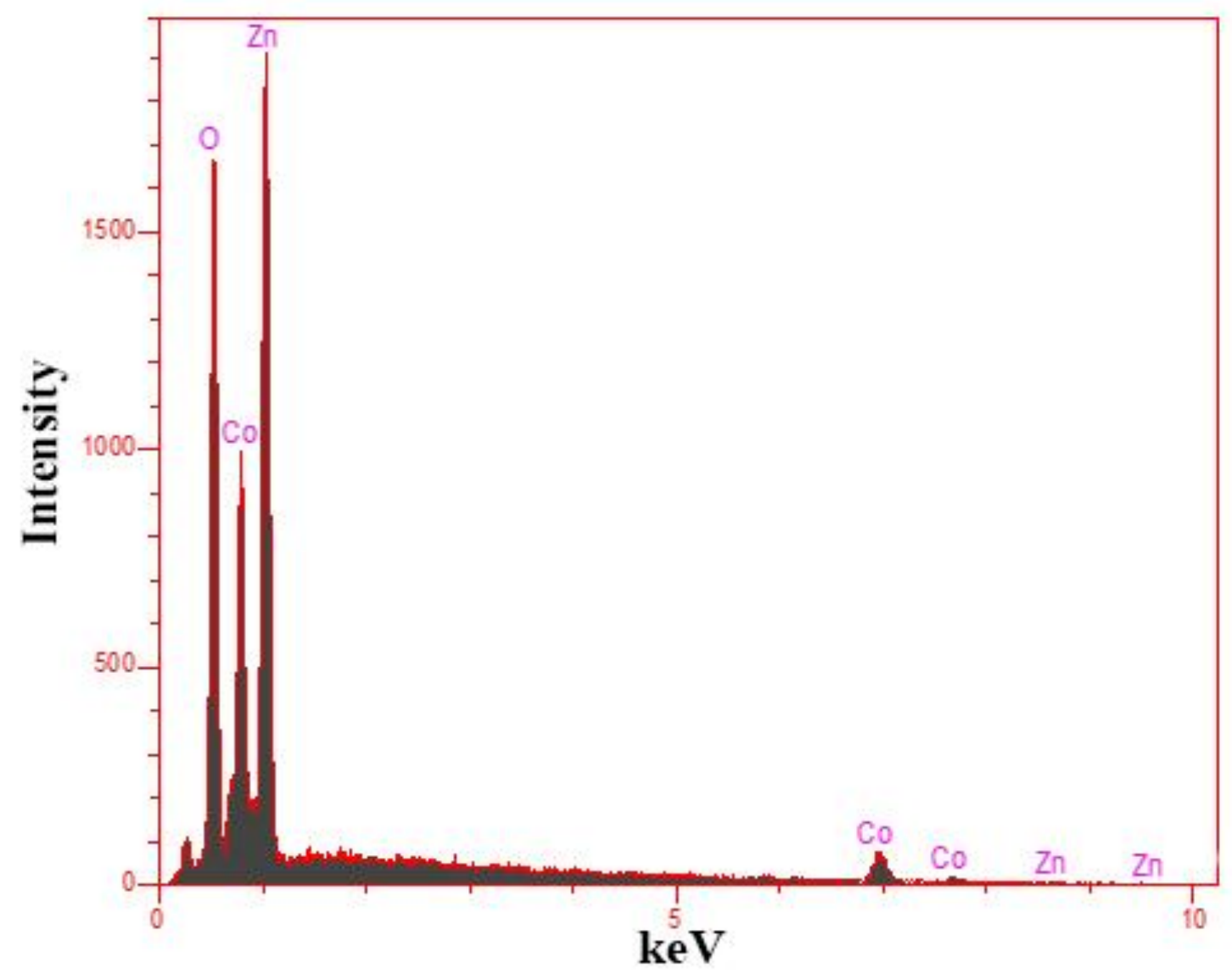


Fig. 4

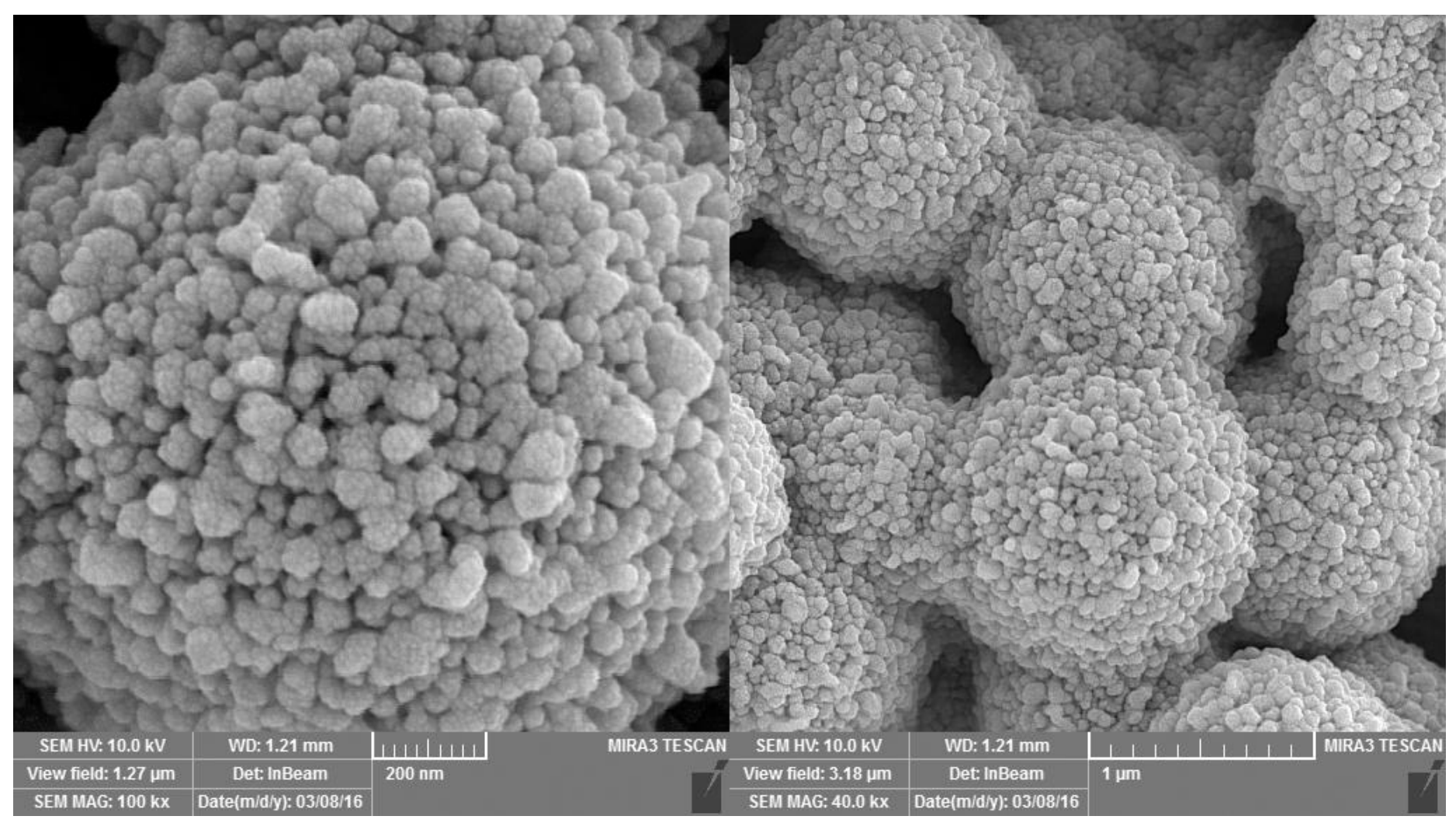


Fig. 5

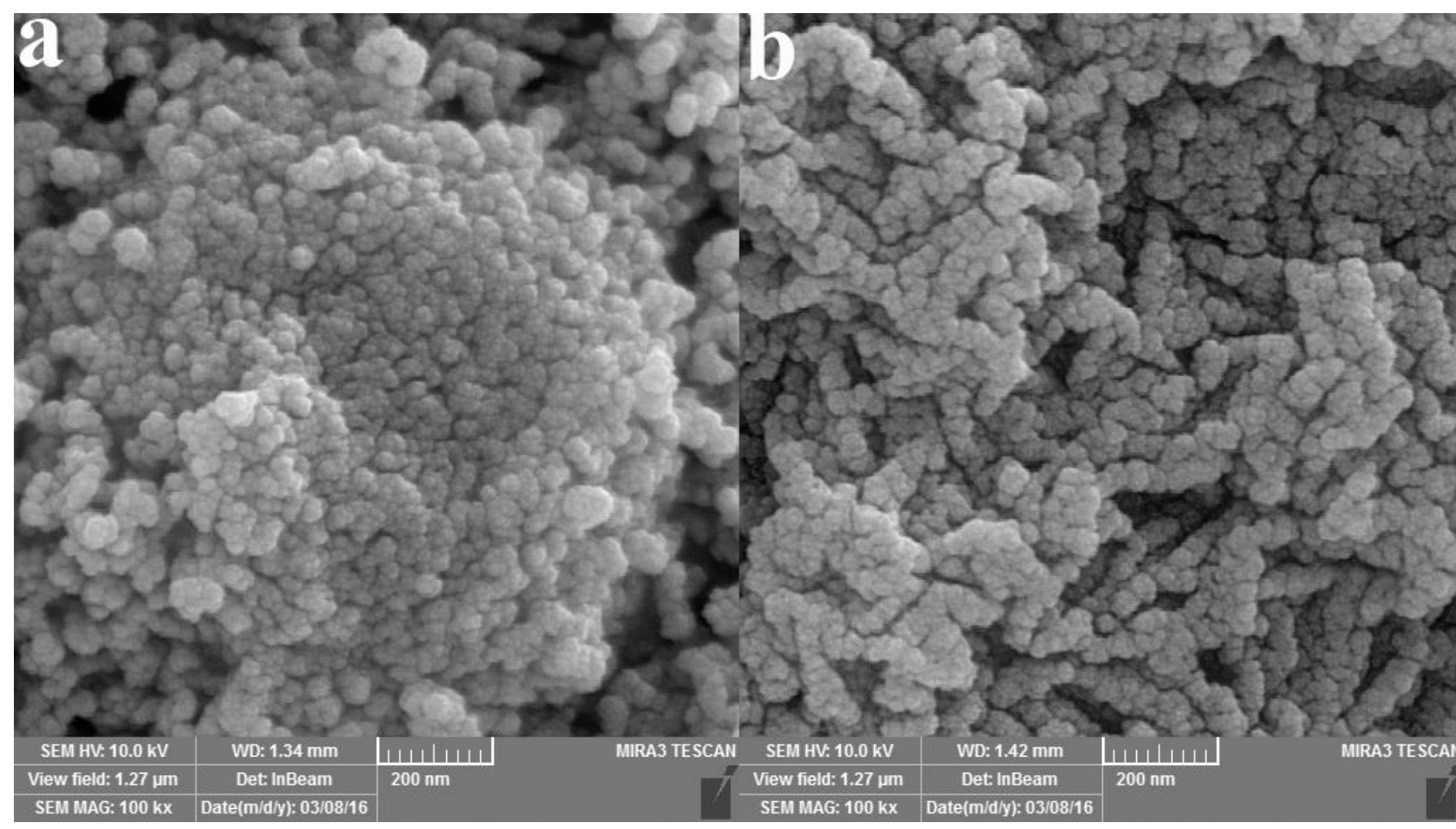


Fig. 6
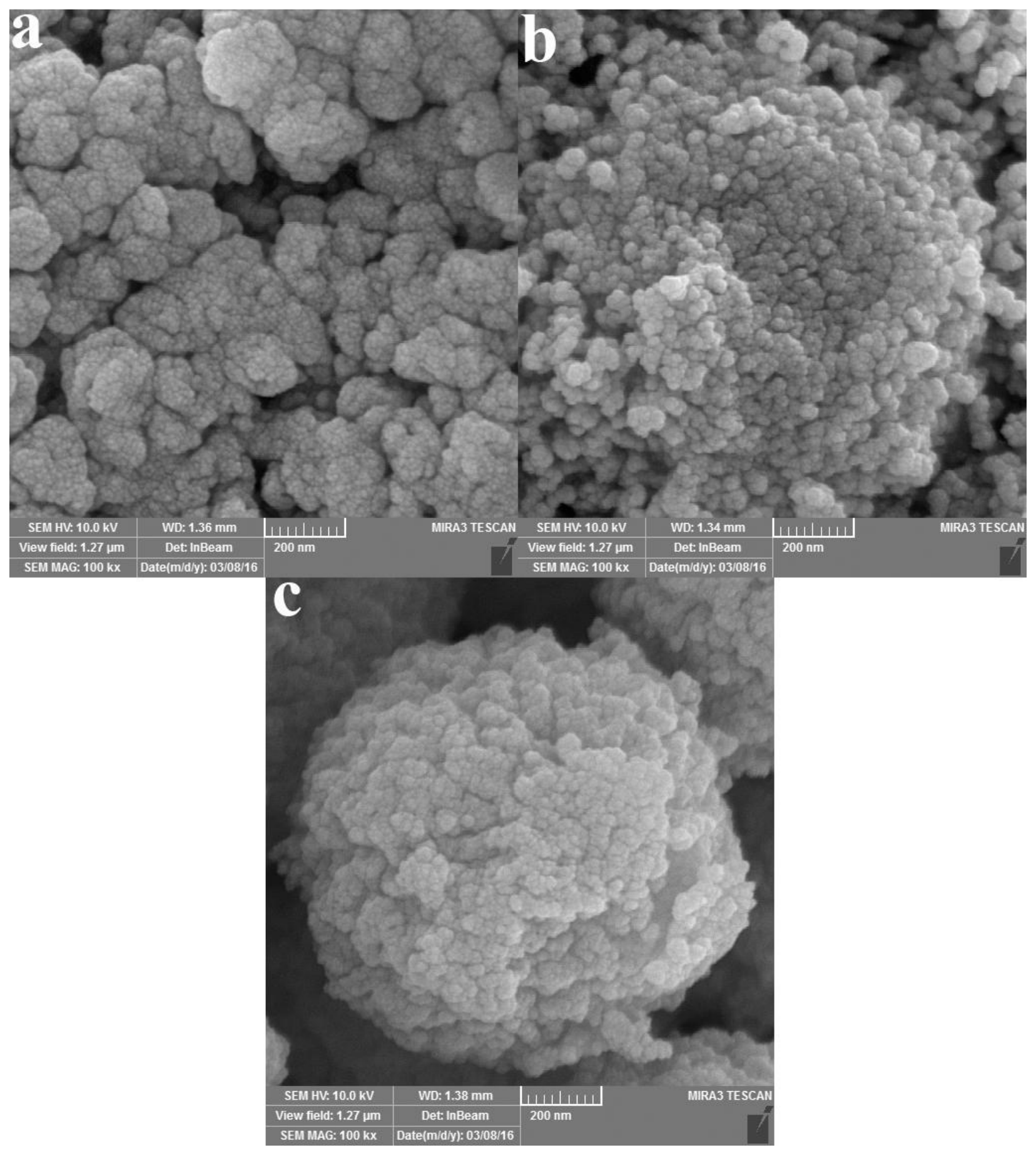
Fig. 7

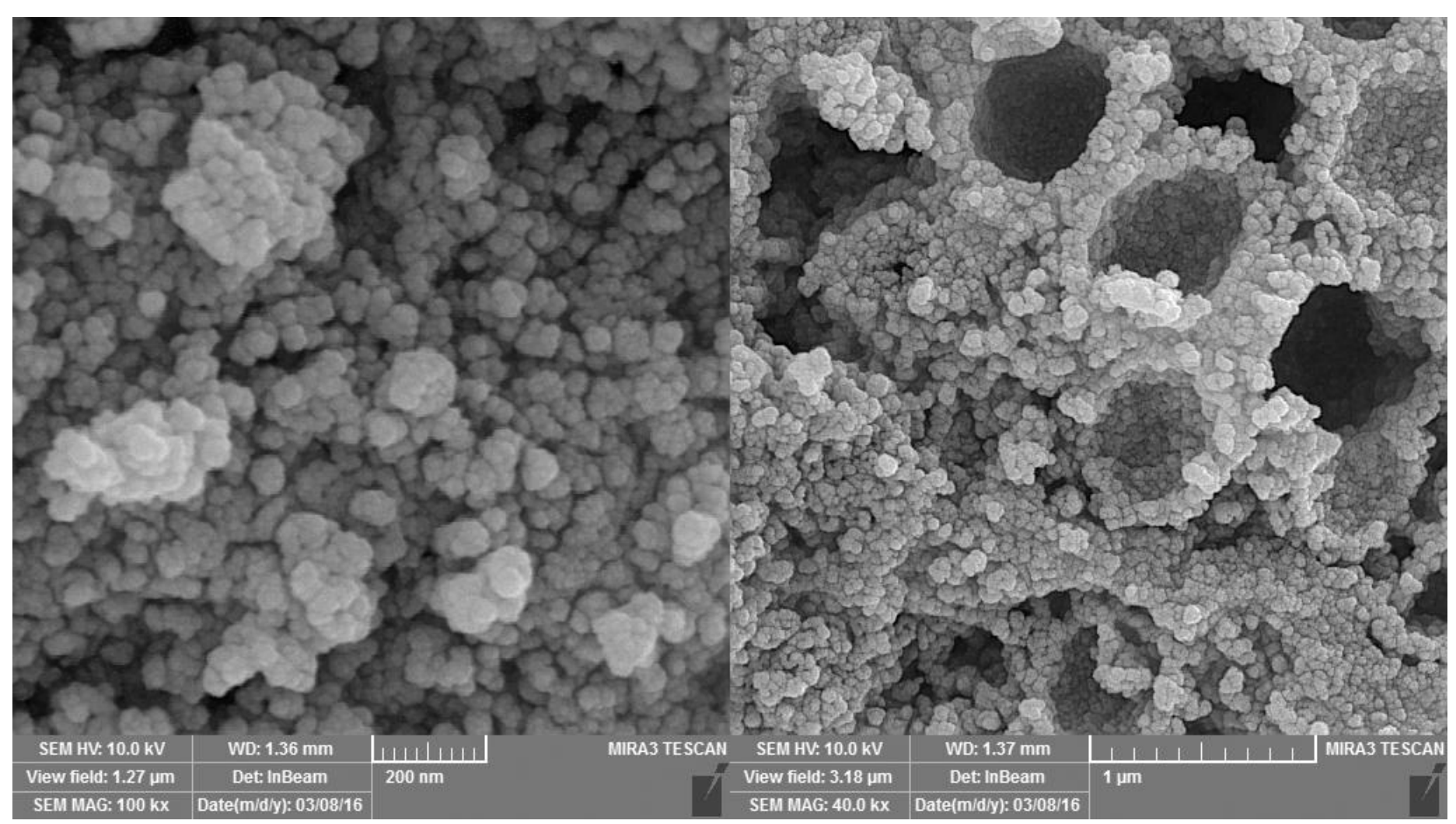


Fig. 8

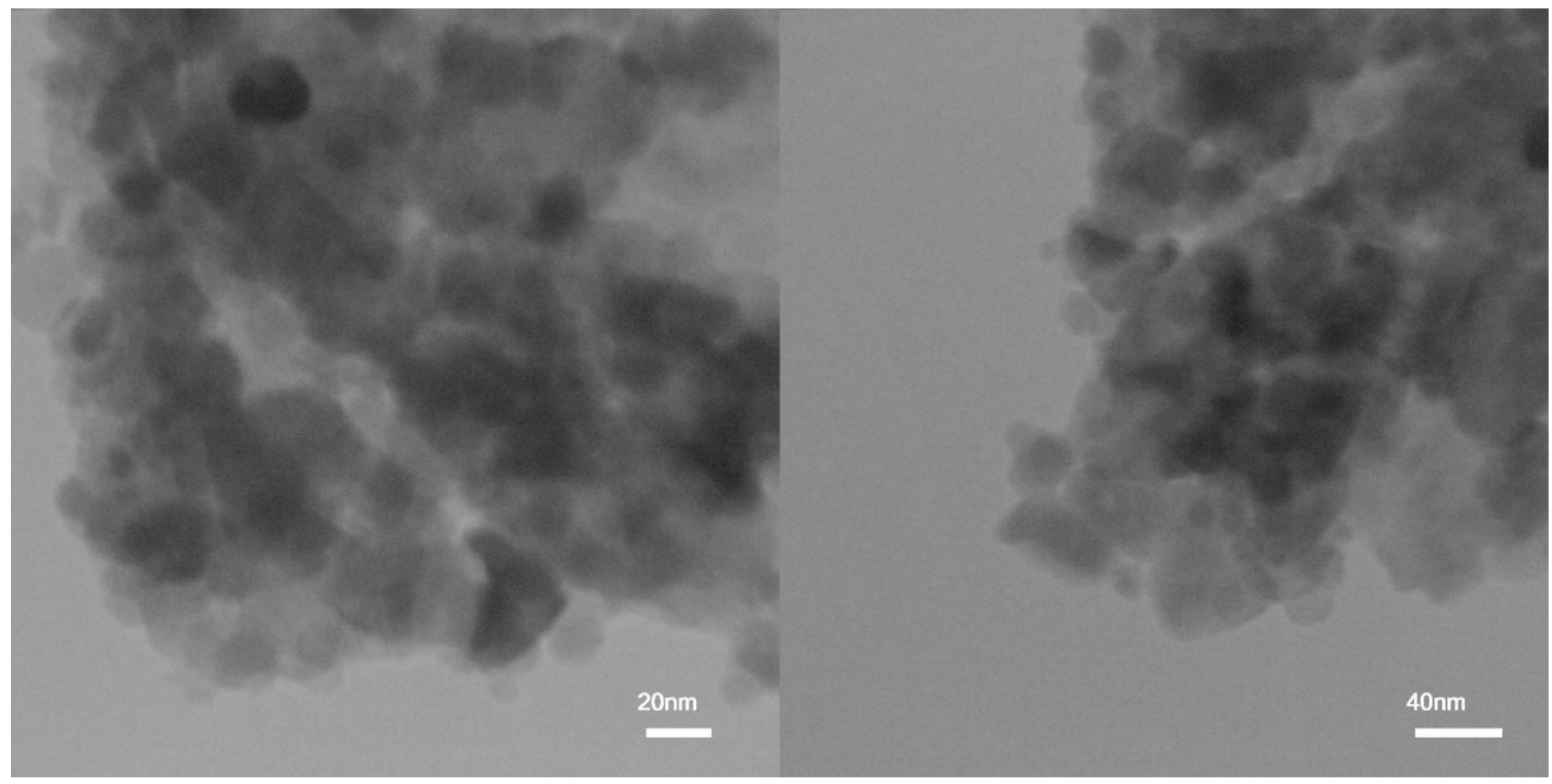


Fig. 9

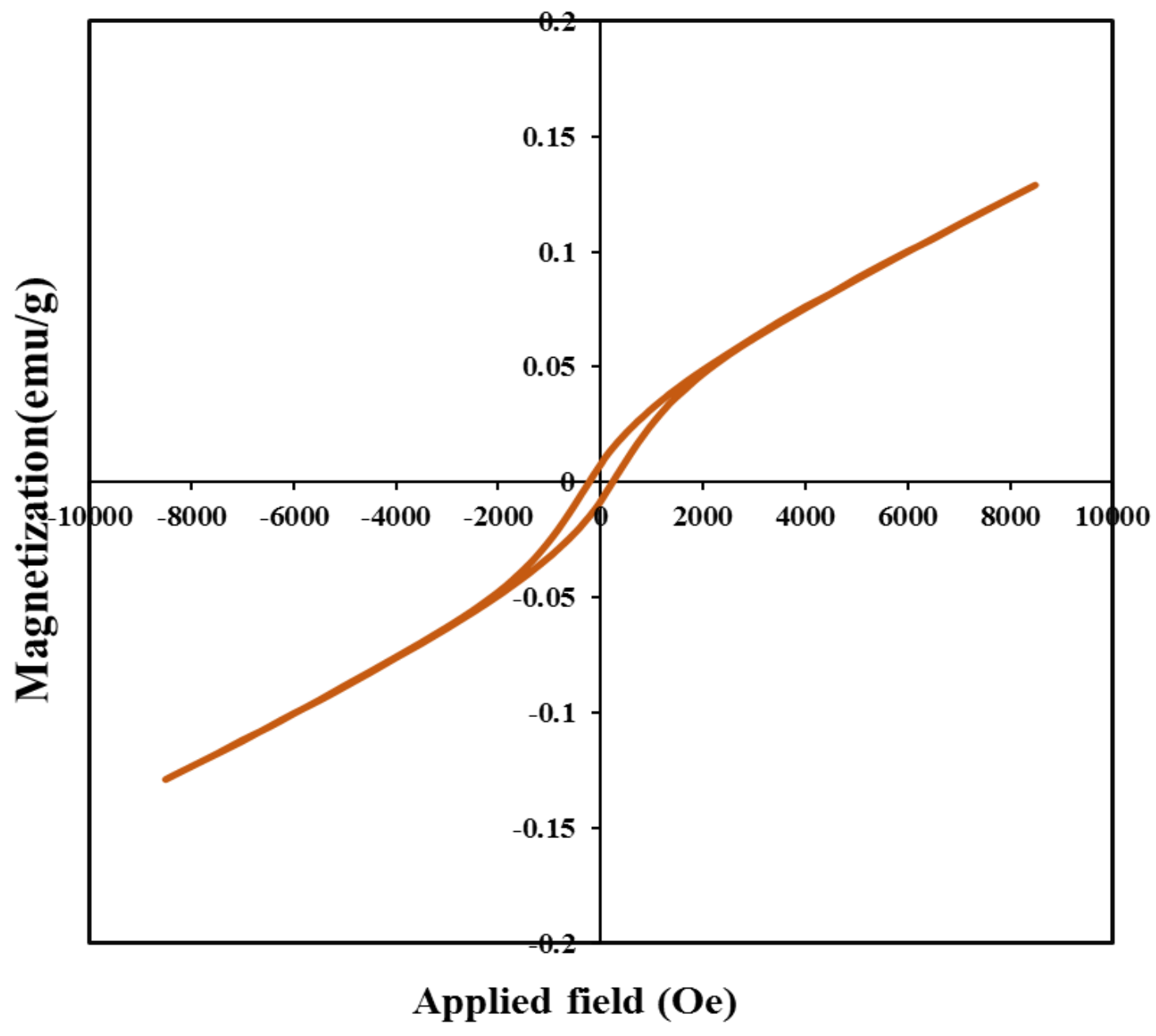


Fig. 10

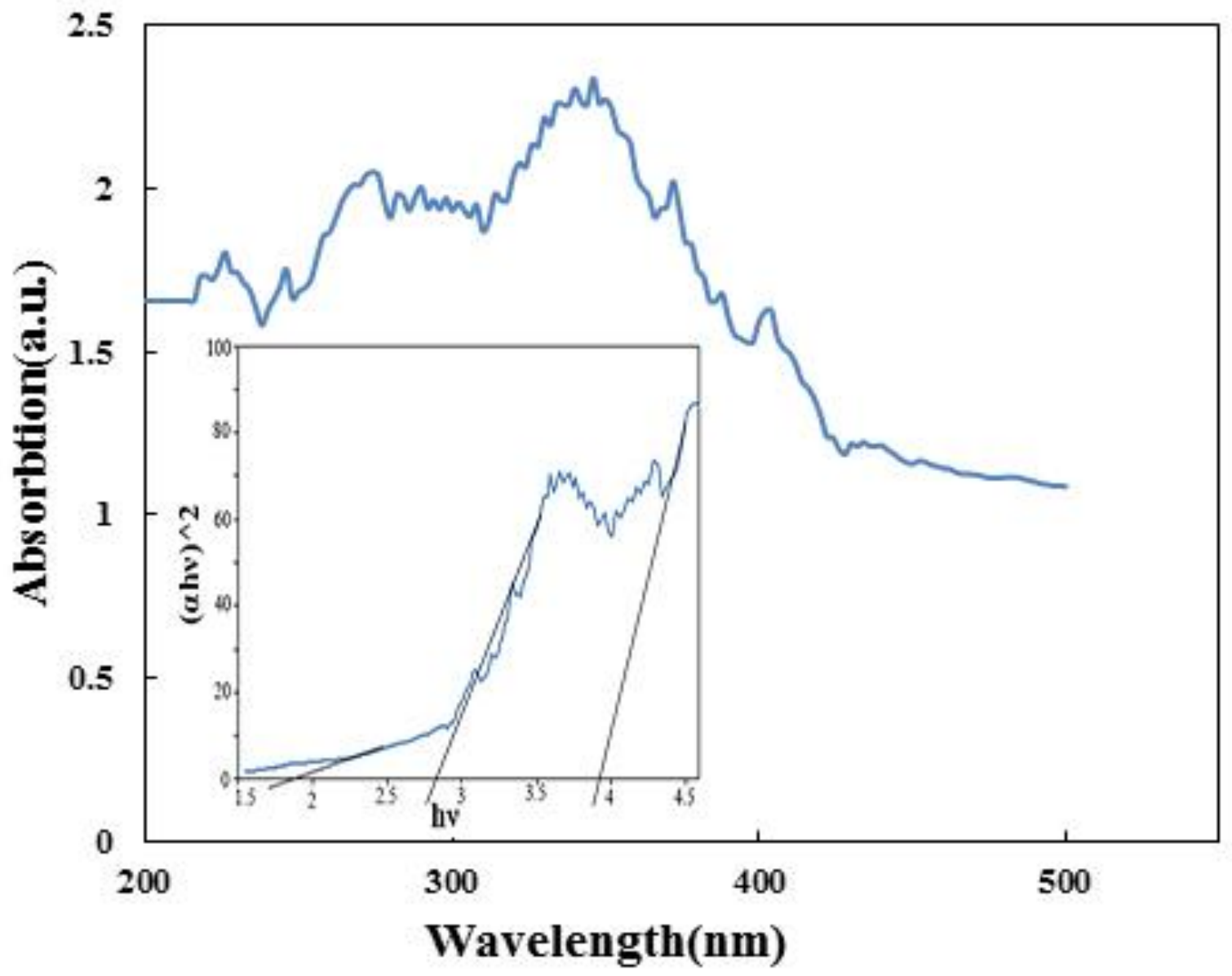


Fig. 11

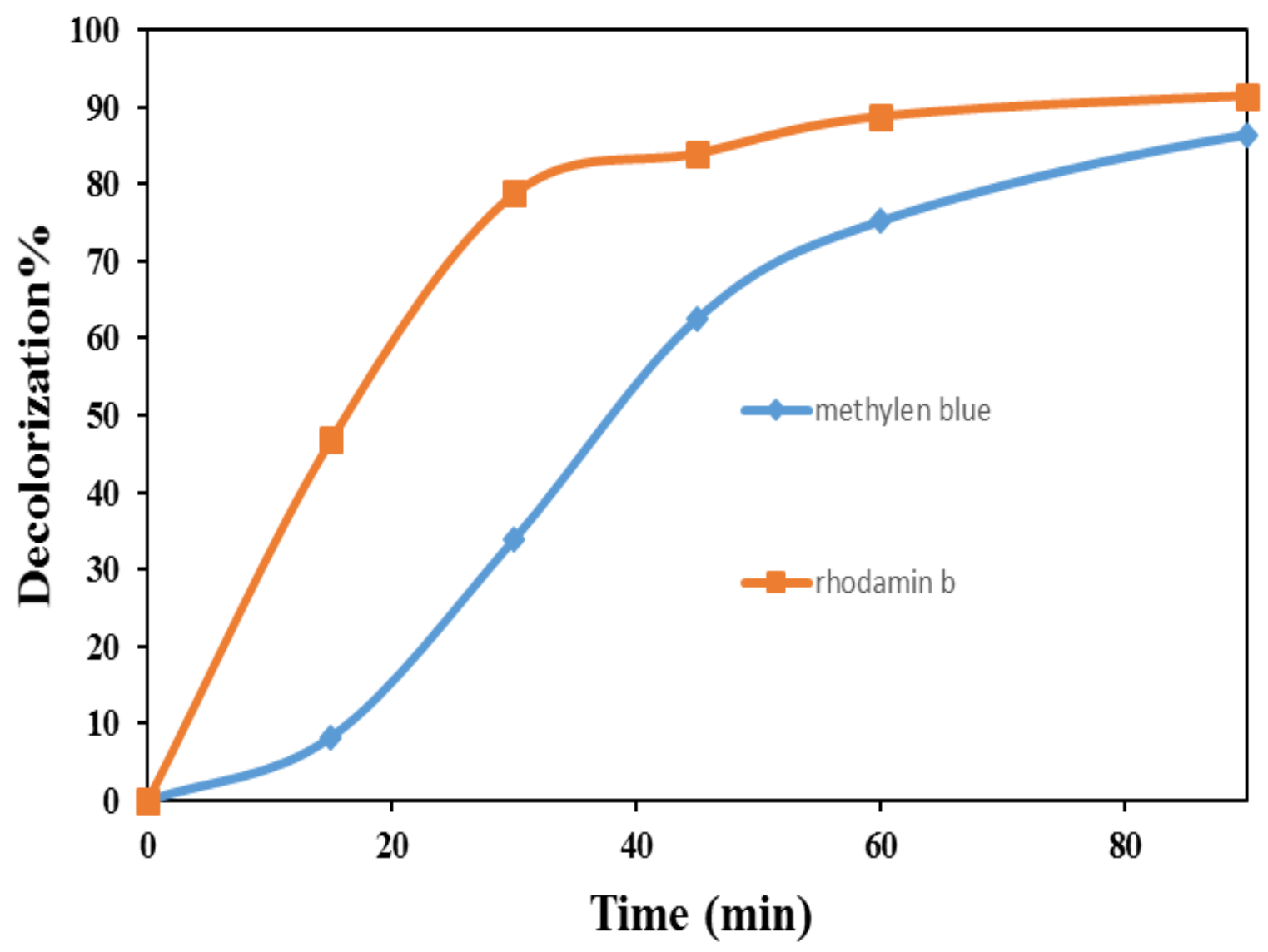




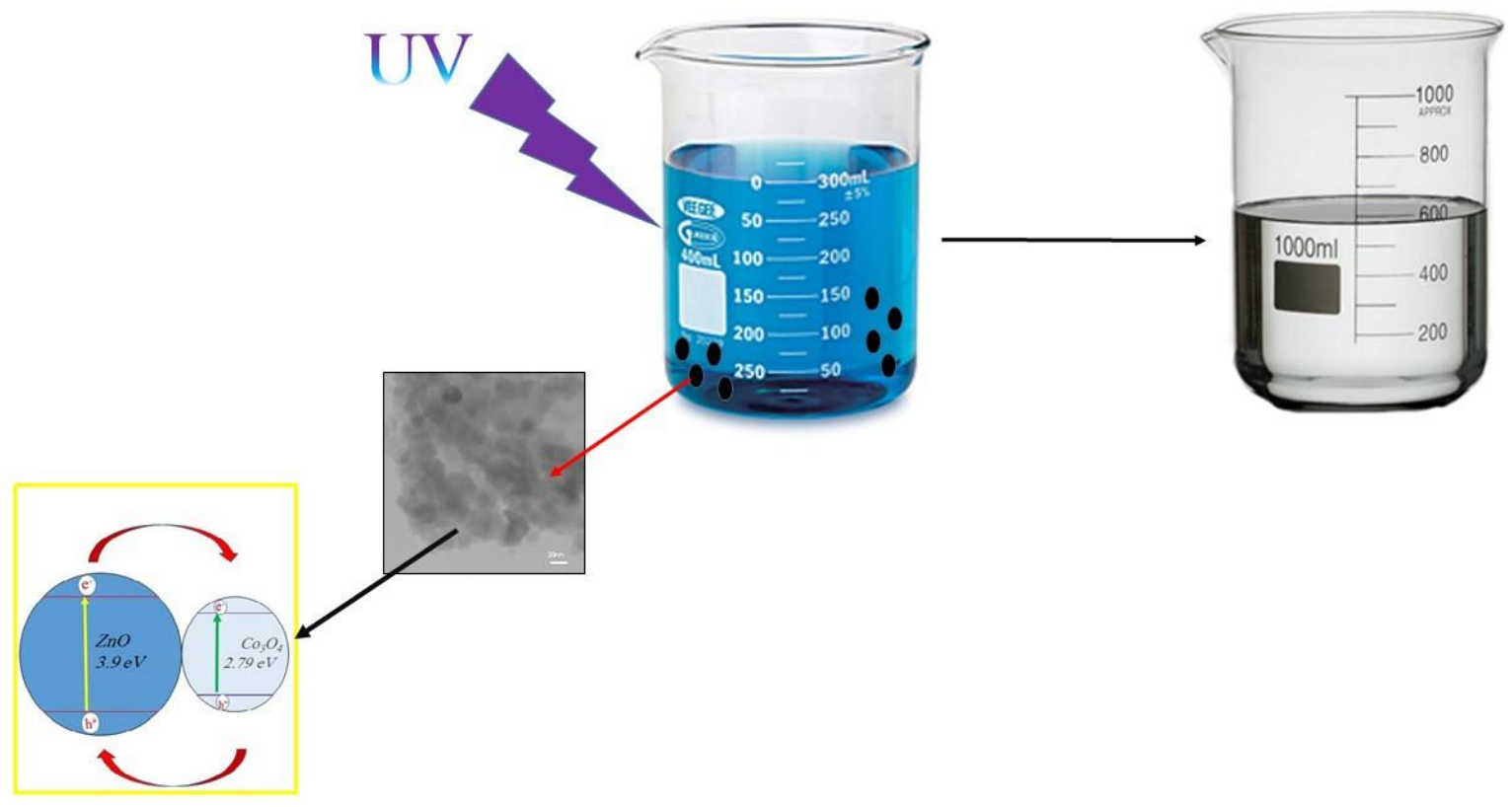

